Revue

Revue de l'histoire des religions

de Ihistoire

des religions

$1 \mid 2008$

Varia

\title{
Nicolas Trigault S. J., Les triomphes chrétiens des martyrs du Japon (1624)
}

\section{Ralph Dekoninck}

\section{(2) OpenEdition}

\section{Journals}

Édition électronique

URL : http://journals.openedition.org/rhr/5823

DOI : $10.4000 /$ rhr.5823

ISSN : 2105-2573

\section{Éditeur}

Armand Colin

\section{Édition imprimée}

Date de publication : 1 mars 2008

Pagination : 139-140

ISBN : 978-2200-92443-0

ISSN : 0035-1423

\section{Référence électronique}

Ralph Dekoninck, « Nicolas Trigault S. J., Les triomphes chrétiens des martyrs du Japon (1624) », Revue de l'histoire des religions [En ligne], 1 | 2008, mis en ligne le 12 janvier 2010, consulté le 22 septembre 2020. URL : http://journals.openedition.org/rhr/5823 ; DOI : https://doi.org/10.4000/rhr. 5823

Ce document a été généré automatiquement le 22 septembre 2020.

Tous droits réservés 


\title{
Nicolas Trigault S. J., Les triomphes chrétiens des martyrs du Japon (1624)
}

\author{
Ralph Dekoninck
}

\section{RÉFÉRENCE}

Nicolas Trigaults. J., Les triomphes chrétiens des martyrs du Japon (1624), nouvelle édition avec introduction, notes et commentaires par Susumu Kudo, Florence Levet, JeanPierre Levet, Catherine Liébert et Yves Liébert, Limoges, Presses Universitaires de Limoges, 2005, 267 p., 24 cm, $18 €$ (coll. « Tôzai. Orient et Occident. Humanisme et langues ", hors-série $n^{\circ} 1$ ).

1 Il convient de saluer l'initiative de la nouvelle collection Tôzai. Orient et Occident. Humanisme et Langues, née d'un partenariat entre l'Université Meiji Gakuin de Tokyo et l'Université de Limoges, d'éditer, comme premier numéro hors-série, Les triomphes chrétiens des martyrs du Japon du Père jésuite Nicolas Trigault. Dans la rencontre entre l'Occident et l'Orient, et particulièrement le Japon, que cette collection met en exergue, une place de choix devait en effet être réservée à cet ouvrage incontournable pour quiconque s'intéresse à un épisode important de l'histoire religieuse du Japon (1612-1620), et plus encore à ses répercussions sur l'imaginaire occidental de cette contrée au XVII ${ }^{\mathrm{e}}$ siècle.

2 Il s'agit en fait de l'édition des deux premiers livres traduits du latin en français par Pierre Morin en 1624 (les trois autres livres seront publiés par la suite dans la même collection) composant cette vaste fresque historique que le Père Trigault, éminent mathématicien et sinologue, publia en latin à Munich en 1623. S'il est resté célèbre essentiellement pour son activité missionnaire en Chine, où il s'est rendu à deux reprises et où il succédera à Matteo Ricci, il ne s'est jamais rendu au Japon, l'hostilité à l'égard de la religion chrétienne qui y régnait, après une période de relative tolérance, 
l'ayant certainement dissuadé d'entreprendre une telle expédition. Les nombreuses inexactitudes historiques et géographiques trahissent en effet une méconnaissance du contexte politique et religieux, faute d'une expérience de terrain. Ses Triomphes chrétiens sont plutôt le fruit d'une collecte d'informations auprès de missionnaires et de commerçants à propos des persécutions de chrétiens qui font rage au début du XVII siècle au Japon.

Il ne faut pas se tromper sur la finalité de son entreprise éditoriale: sa visée apologétique est on ne peut plus claire. L'ouvrage est construit à la "gloire des saints japonais et des éminents et réels mérites dont ils ont fait publiquement preuve ». Il s'agit donc bien d'une sorte de martyrologe dont la portée est fondamentalement édifiante : ce qui compte est la dimension miraculeuse du martyre, dont les souffrances, décrites avec force détails, ne sont que l'expression des combats intérieurs qui mènent inéluctablement à la palme de la victoire. Nous avons affaire à une véritable tragédie pour reprendre le terme même de l'auteur (p. 33) - qui rappelle que ce genre de récit a pu servir de matière première au théâtre jésuite, lequel puisera à foison dans cette littérature où se rejouent en terres exotiques les premières persécutions chrétiennes. D'où la présence en abondance des topoi empruntés à la tradition et permettant de conjuguer les temps passé et présent. Le réalisme des descriptions, qui le disputent au caractère flou des circonstances géographico-politiques, se trouve par ailleurs renforcé par l'illustration qui accompagnait l'ouvrage dès sa première édition et qui rappelle les stratégies visuelles du Théâtre des cruautés d'un Verstegen (1587). On peut à ce titre regretter que cette édition ne reproduise pas les images, qui, il est vrai, sont plus présentes à partir du troisième livre. Le frontispice aurait également pu être reproduit, montrant saint Ignace et saint François-Xavier en adoration devant un tronc d'arbre ceint du signe de la Croix. De même, l'apparat critique ou les commentaires, réduits à leur plus simple expression, auraient mérité d'être étoffés afin de rendre compte plus en détail du cadre idéologique de l'ouvrage comme des multiples emprunts faits à la littérature martyrologique du siècle précédent. L'intérêt d'une présentation épurée réside néanmoins dans la rapide mise à disposition d'un texte fondamental et d'une grande richesse quant à l'histoire des missions au Japon. On peut dès lors espérer que les trois autres livres ne tarderont pas à paraître.

\section{AUTEURS}

\section{RALPH DEKONINCK}

Université catholique de Louvain 